\title{
Revised Operational Classification of Seizure Types
}

\author{
Robert S Fisher \\ Stanford University School of Medicine, Stanford, CA, US
}

he International League Against Epilepsy (ILAE) issued a revised operational classification of seizure types. The ILAE retained much of the old structure, but new features include new types of focal motor seizures: automatism, tonic, atonic, myoclonic, hyperkinetic, and spasm motor seizures. Focal nonmotor seizures can be autonomic, behavior arrest, cognitive, emotional, and sensory. A few new generalized types are included, as well as seizures of unknown onset. Partial is renamed focal. Simple partial is renamed focal aware and complex partial, focal impaired awareness. The new classification should enhance clarity and communication.

\section{Keywords}

Epilepsy, seizure, classification

Disclosure: Robert S Fisher has nothing to disclose in relation to this article. No funding was received for the publication of this article. This article is a short opinion piece and has not been submitted to external peer reviewer, but was reviewed by the editorial board for accuracy before publication.

Authorship: All named authors meet the International Committee of Medical Journal Editors (ICMJE) criteria for authorship of this manuscript, take responsibility for the integrity of the work as a whole, and have given final approval for the version to be published.

open Access: This article is published under the Creative Commons Attribution Noncommercial License, which permits any noncommercial use, distribution, adaptation, and reproduction provided the original author(s) and source are given appropriate credit.

Received: April 16, 2017

Published Online: July 24, 2017

Citation: US Neurology, 2017;13(2):72-3

Corresponding Author: Robert S Fisher, Department of Neurology and Neurological Sciences, 213 Quarry Road, Room 4865, Palo Alto, CA 94304-5979, US.

E: robert.fisher@stanford.edu
In April 2017, the International League Against Epilepsy (ILAE), which is the parent body of over 100 national professional epilepsy societies, published a revised operational classification of seizure types $^{1-4}$ and epilepsies. ${ }^{5}$ The seizure classification was a revision of the classification established in $1981^{6}$ and partially updated in $2010 .^{7}$ The 1981 classification, which included the terms simple partial and complex partial seizures, had some limitations. There was no specific mention of several focal motor seizure types, such as atonic, myoclonic, or tonic, which could only appear as generalized seizures. Seizures, for example tonic-clonic, could not be classified if the onset was unknown. Some important generalized onset seizure types were missing. Certain terms, such as partial, simple, complex, and psychic, were not clear to the public and even to some physicians. Using consciousness to classify seizures was sometimes confusing, since unconsciousness or impaired consciousness meant different things to different people. In some studies, more than half of the people with epilepsy misclassified their seizure type. ${ }^{8}$

Figure 1 illustrates the expanded ILAE 2017 classification of seizures. A basic version can be constructed by eliminating the small font subcategories. This classification is empirical and based upon an extension of the 1981 system, since we do not yet know enough to classify according to the underlying science of epilepsy.

Partial seizures are renamed focal seizures. Seizures are classified as focal with onset in one hemisphere, versus generalized with onset in both hemispheres or seizures of unknown onset. For focal seizures, the next optional classifier is by level of awareness, which serves as a surrogate for consciousness. A seizure is focal aware (previously 'simple partial') if awareness is retained and focal impaired awareness (previously 'complex partial') if awareness is disturbed for any part of the seizure. The next optional categorization is into motor and nonmotor focal seizures, with specific types listed in Figure 1. The specific focal seizure subclassification derives from the first manifestation of a seizure, even if that is not the most prominent behavior, because the first manifestation marks the onset zone (seizure focus or network). For example, an event with chills and piloerection, followed by impaired awareness and tonic stiffening of the right arm is a focal impaired awareness autonomic seizure. It is always acceptable to add other descriptive terms (a standard set is suggested²), but these do not change the classification. A 'secondarily generalized tonic-clonic seizure' is renamed as focal to bilateral tonic-clonic seizure. 
Figure 1: ILAE 2017 classifications of seizure types (expanded version) ${ }^{3}$

\begin{tabular}{|c|c|c|c|}
\hline \multicolumn{2}{|c|}{ Focal onset } & Generalized onset & Unknown onset \\
\hline Aware & $\begin{array}{l}\text { Impaired } \\
\text { awareness }\end{array}$ & \multirow{5}{*}{$\begin{array}{l}\text { Motor } \\
\text { tonic-clonic } \\
\text { clonic } \\
\text { tonic } \\
\text { myoclonic } \\
\text { myoclonic-tonic-clonic } \\
\text { myoclonic-atonic } \\
\text { atonic } \\
\text { epileptic spasms } \\
\text { Non-motor (absence) } \\
\text { typical } \\
\text { atypical } \\
\text { myoclonic } \\
\text { eyelid myoclonia }\end{array}$} & $\begin{array}{l}\text { Motor } \\
\text { tonic-clonic }\end{array}$ \\
\hline \multirow{4}{*}{\multicolumn{2}{|c|}{$\begin{array}{l}\text { Motor onset } \\
\text { automatisms } \\
\text { atonic* } \\
\text { clonic } \\
\text { epileptic spasms* } \\
\text { hyperkinetic } \\
\text { myoclonic } \\
\text { tonic } \\
\text { Non-motor onset } \\
\text { autonomic } \\
\text { behavior arrest } \\
\text { cognitive } \\
\text { emotional } \\
\text { sensory }\end{array}$}} & & $\begin{array}{l}\text { Non-motor } \\
\text { behavior arrest }\end{array}$ \\
\hline & & & Unclassified** \\
\hline & & & \\
\hline & & & \\
\hline focal to bil & al tonic-clonic & & \\
\hline
\end{tabular}

*Degree of awareness usually not specified. ${ }^{*}$ DDue to inadequate information or inability to place in other categories. ILAE = International League Against Epilepsy. Reprinted with permission of Wiley Publishing.
Generalized onset seizures rarely associate with retained awareness, so the subcategorization is directly into motor and nonmotor/absence. Types are similar to those of the 1981 classification, but a few new types have been added. The unknown onset category is a placeholder, so an unknown onset seizure may be revised to focal or generalized onset if more information becomes available. Behavior is the key to classification, but ancillary information, particularly electroencephalography (EEG), can aid classification when such information is available.

Also available is a new classification of the epilepsies, ${ }^{5}$ which accounts for whether the patient has focal, generalized, or mixed seizure types; etiologies; neuroimaging; immunologic or genetic findings; epilepsy syndromes; various prognoses and comorbidities; and other important factors in the overall clinical picture. The netresult of the new classifications, once past a learning and adoption period, should be greater clarity of understanding by the medical community, public, and patients about their seizures and epilepsy.
1. Fisher RS, An overview of the 2017 ILAE operational classification of seizure types, Epilepsy Behav, 2017;70:271-3.

2. Fisher RS, Cross JH, D'Souza C, et al., Instruction manual for the ILAE 2017 operational classification of seizure types, Epilepsia, 2017; 58:531-42.

3. Fisher RS, Cross JH, French JA, et al., Operational classification of seizure types by the International League Against Epilepsy: position paper of the ILAE Commission for Classification and
Terminology, Epilepsia, 2017; 58:522-30

4. Sperling MR, New definition and classifications of epilepsy among highlights of the American Epilepsy Society annual meeting. US Neurology, 2017:13:13-5.

5. Scheffer IE, Berkovic S, Capovilla G, et al., ILAE classification of the epilepsies: position paper of the ILAE Commission for Classification and Terminology, Epilepsia, 2017;58:512-21. 6. Proposal for revised clinical and electroencephalographic classification of epileptic seizures. From the Commission on Classification and Terminology of the International League Against Epilepsy, Epilepsia, 1981;22:489-501.

7. Berg AT, Millichap JJ, The 2010 revised classification of seizures and epilepsy, Continuum (Minneap Minn), 2013;19:571-97.

8. Mameniskiene R, Sakalauskaite-Juodeikiene E, Budrys V, People with epilepsy lack knowledge about their disease, Epilepsy Behav 2015;46:192-7. 